\title{
Sosyotelist Olma ve Sosyotelizme Maruz Kalma Ölçeklerinin Türkçeye Uyarlanması
}

\author{
Adaptation of General Scales of Phubbing and Being Phubbed into Turkish
}

\author{
Arş. Gör. Dr. Derya ORHAN GÖKSÜN (iD) 1
}

\begin{abstract}
$\ddot{\mathbf{O z}}$
Son yıllarda araştırmalara konu olan sosyotelizm; bireyin başka bireylerle iletişimi sırasında dikkatini akıllı telefona vermesi, akıllı telefonla ilgilenmesi ve algısını kişilerarası iletişimden kaçırması olarak tanımlanmaktadır. Bir sosyotelist ile etkileşimde bulanan başka bir bireyin, sosyotelistin kendisi ile ilgilenmeyip telefonu ile ilgilenmesi, sosyal etkileşim gerçekleşmesi gereken herhangi bir ortamda etkili vakit geçiremeyip durumdan olumsuz etkilenmesine neden olması da sosyotelizme maruz kalma olarak nitelendirilmektedir. Bu çalışmada Genel Sosyotelist Olma (GSO) ve Genel Sosyotelizme Maruz Kalma (GSMK) ölçeklerinin Türkçeleştirilmesi çalışması yürütülmüştür. Ölçek uyarlamanın çeviri sürecinde dört uzman ve sekiz öğretmen adayı, doğrulayıcı faktör analizi sürecinde ise yaş ve cinsiyet açısından çeşitlendirilmiş 180 gönüllü katılımcı yer almıştır. Veri toplama araçları Chotpitayasunondh ve Douglas (2018a) tarafından geliştirilen GSO ve GSMK ölçeklerinin Türkçeleştirilmiş formlarıdır. Toplanan veriler doğrulayıcı faktör analizi ile çözümlenerek sözü edilen ölçeklerin Türkçeye uyarlanması gerçekleştirilmiştir. GSO ölçeğinin özgün ölçekte öne sürülen dört faktör 15 maddeden oluşan yapısı doğrulanmıştır $\left(\chi^{2} / \mathrm{sd}=1.99, \mathrm{p}<0.001, \mathrm{RMSEA}=0.07, \mathrm{SRMR}=0.06, \mathrm{NFI}=0.92, \mathrm{CFI}=0.96, \mathrm{GFI}=0.89\right)$. Benzer biçimde GSMK ölçeğinin özgün formunda öne sürülen üç faktör 22 maddeden oluşan yapısı doğrulanmıştır $\left(\chi^{2} / \mathrm{sd}=2.04, \mathrm{p}<0.001, \mathrm{RMSEA}=0.08, \mathrm{SRMR}=0.07, \mathrm{NFI}=0.90, \mathrm{CFI}=0.95, \mathrm{GFI}=0.82\right)$. Ölçekler için yol diyagramlarında tanımlanan yollar, $\mathrm{t}$ ve $\mathrm{R}^{2}$ değerleri anlamlıdır $\left(\alpha_{\mathrm{GSO}}=0.78, \alpha_{\mathrm{GSMK}}=\right.$ $0.87)$.
\end{abstract}

Anahtar Kelimeler: Sosyotelizm, sosyotelist, sosyotelizme maruz kalma, ölçek uyarlama.

Makale Türü: Araştırma

\begin{abstract}
Phubbing, is mentioned frequently researches in recent years, occurs when people care their smart phones and ignore other people instead interpersonal communication or interaction during a meeting or another social environment. Phubbee, in other words being phubbed, is defined as person who interact with a phubber, care smart phone instead communicate with him/her, because of this situation affected negatively in an environment where should occur social interactions, but not. At this study, adaptation into Turkish of Generic Scale of Phubbing (GSP) and Generic Scale of Being Phubbed (GSBP) scales studies were conducted. The participants were four experts and eight pre-service teachers during translation process, 180 participants, who were in different ages and gender, during confirmatory factor analysis process. The data were collected via Turkish forms of GSP and GSBP developed by Chotpitayasunondh, \& Douglas (2018a) and analyzed via confirmatory factor analysis technique. The structure of GSP, suggested on original paper, was confirmed $\left(\chi^{2} / \mathrm{df}=1.99, \mathrm{p}<0.001, \mathrm{RMSEA}=0.07\right.$, $\mathrm{SRMR}=0.06, \mathrm{NFI}=0.92, \mathrm{CFI}=0.96, \mathrm{GFI}=0.89)$. Similarly, the structure of GSBP, suggested on original paper, was confirmed $\left(\chi^{2} / \mathrm{df}=2.04, \mathrm{p}<0.001\right.$, RMSEA $=0.08, \mathrm{SRMR}=0.07, \mathrm{NFI}=0.90, \mathrm{CFI}=0.95$, GFI $=$ $0.82)$. The path diagrams, $t$ and $R^{2}$ values are significant of both scales $\left(\alpha_{\mathrm{GSP}}=0.78, \alpha_{\mathrm{GSBP}}=0.87\right)$.
\end{abstract}

Keywords: Phubbing, phubbee, phubber, being phubbed, scale adaptation.

Paper Type: Research

\footnotetext{
${ }^{1}$ Adıyaman Üniversitesi, Eğitim Fakültesi, dorhan@ adiyaman.edu.tr.

Atıf için (to cite): Orhan Göksün, D. (2019). Sosyotelist Olma ve Sosyotelizme Maruz Kalma Ölçeklerinin Türkçeye Uyarlanması. Afyon Kocatepe Üniversitesi Sosyal Bilimler Dergisi, 21(3), 657-671.
} 


\section{Giriş}

Günlük yaşantımızın en büyük gereksinimlerinden biri iletişimdir. Başlangıçta iletişim gereksinimi kolayca karşılayabilmek ve bireyleri her yerde ulaşılabilir kılmak amacı ile kullanılan cep telefonlarının özellikleri her geçen gün farklılaşmıştır. Günümüzde cep telefonlarının birincil amacı olan iletişim gereksinimi öncelikli yerini eğlence, sosyalleşme, günlük işleri yürütme gibi işlevlere bırakmıştır. Özellikle sosyalleşme gereksinimin bu derece kolay ulaşılabilir bir teknoloji ile karşılanabilmesi yüz yüze ilişkilerde çeşitli sorunların yaşanmasına neden olmuştur. $\mathrm{Bu}$ konularda alanyazında dile getirilen sorunlardan biri sosyotelizmdir.

Son yıllarda araştırmalara konu olan sosyotelizm; bireyin başka bireylerle iletişimi sırasında dikkatini akıllı telefona vermesi, akıllı telefonla ilgilenmesi ve algısını kişilerarası iletişimden kaçırması (Karadağ ve ark., 2016) olarak tanımlanmaktadır. Başka bir deyişle sosyotelizm; çevresindekileri görmezden gelerek, zamanı Facebook kullanarak, Whatsapp ya da başka bir sohbet programında yazışarak vb. etkinliklerle geçirme eylemidir (Nazir ve Pişkin, 2016). Alanyazında bu durum genel olarak bağımlılık olarak tanımlanmakta ve sosyal bir davranış bozukluğu olarak değerlendirilmektedir. Karadağ ve ark. (2016) sosyotelist davranışların akıllı telefon, oyun, sosyal medya, oyun ve uygulama bağımlılıkları ile ilişkili olduğunu savunmaktadırlar. Chotpitayasunondh ve Douglas (2016) benzer biçimde, sosyotelist davranışlar ile akıllı telefon bağımlılığı, internet bağımlılığı ve gelişmeleri kaçırma korkusu arasında ilişki olduğunu ortaya çıkarmıştır. Ancak sözü edilen bu davranışlar ile ilişkili olmasına karşın bu davranışların bütün özelliklerini taşıdığı ya da kapsadığı düşünülmemelidir. Örneğin sosyotelist bir birey, akıllı telefon ya da internet bağımlısı olmayabilir. Bu bireyin sosyotelist davranışların kaynağı sadece o an karşısında bulunan kişi ile ilişki kurmak istemeyişi olabilir. Daha açık bir ifade ile sosyotelist bir birey sözü edilen bağımlılıkların bütün özelliklerini de gösterebilir, bir takım belirtileri de sergileyebilir veya bireyde bu bağımlıklara ilişkin herhangi bir iz görülmeyebilir. Bu durum sosyotelizmin sözü edilen kavramlardan bazı noktalarda ayrılması gerektiğini ve sosyotelizmin kaynakları ve sınırları henüz alanyazında çizilemediğini düşündürmektedir.

Sosyotelist bireylerin sözü edilen davranış bozuklukları sadece kendi yaşamını değil çevresinde etkileşim durumunda olduğu diğer bireyleri de etkilemektedir. Bu durum sosyotelizme maruz kalma olarak nitelendirilmektedir. Daha açık bir ifade ile bir sosyotelist ile etkileşimde bulanan başka bir bireyin, sosyotelistin kendisi ile ilgilenmeyip telefonu ile ilgilenmesi, sosyal etkileşim gerçekleşmesi gereken herhangi bir ortamda etkili vakit geçiremeyip durumdan olumsuz etkilenmesine neden olmaktadır (Chotpitayasunondh ve Douglas, 2018a). Sosyotelizme maruz kalan kişiler çoğunlukla durumdan memnun olmadıklarını (Roberts ve David, 2016), karşısındaki ile bağlantı kuramadıklarını (Krasnova, Abramova, Notter ve Baumann, 2016), temel ihtiyaçlarının özellikle sosyal gereksinimlerinin karşılanmasının engellendiğini (Chotpitayasunondh ve Douglas, 2018b) düşünmektedirler. Karşısındaki ile sosyal bağlantı kuramayan bir bireyin de algısını sosyal etkileşimden çekerek telefona yönlendirme olasılığı oldukça yüksektir. Bu bağlamda bir bireyin hem sosyotelist hem de sosyotelizme maruz kalan konumunda olması da olasıdır. Günümüzde siradan bir yürüyüşümüz sırasında aynı masada çay, kahve tüketen ancak hepsinin ayrı ayrı telefonları ile ilgilenip herhangi bir konuşma ya da paylaşımın olmadığı gruplar görmemizin temel nedeninin bu durum olduğu söylenebilir.

Sosyal davranışların öğrenme ve öğrenme yaşantıları üzerine etkisini irdeleyen birçok çalışma bulunmaktadır. Bunlardan bazıları sosyal davranış bozuklarının öğrenme üzerinde olumsuz etkilerinin olduğunu (Best, 2017; Doel ve Shardlow, 2017), bazıları sosyal davranışların öğrenme yaşantılarını olumlu ya da olumsuz etkilediğini ve şekillendirdiğini (Agostin ve Bain, 1997; Dess, 2017; Ladd, 1990) öne sürmektedirler. Sosyotelist davranışlar eğitsel bağlamda düşünüldügünde durum biraz daha karmaşıklaşmaktadır. Öğrencilerin 
\%98'inin cep telefonu sahibi olduğu (Diamanduros, Jenkins ve Downs, 2007) ve yine öğrencilerin \%62'sinin ödev yaparken, ders çalışırken ya da sınıf ortamında teknoloji kullandıklarını ifade ettikleri (Jacobsen ve Forste, 2011) bir eğitim sistemi için sözü edilen problemli davranışların olumsuz etkilerinin gözlenmesi kaçınılmazdır. Teknolojinin sınıf ortamlarında hızla yaygınlaştığı ve sınıf içinde bireysel teknoloji kullanımının giderek yaygınlaştığı (Good ve Lavigne, 2017) günümüzde, bir teknolojik sosyal davranış sorunu olan "sosyotelizm" ve sosyal olarak sosyotelizmden etkilenme durumunu açıklayan "sosyotelizme maruz kalma" olgularının eğitsel yaşantılar ile birlikte çalışılması gereken olgular olduğu açıktır. Bu bağlamda sözü edilen davranışların ölçümlenmesi ve bireyde bu davranışların ne düzeyde gözlendiğinin belirlenerek önlem alınması gerekmektedir.

Alanyazında sosyotelizmin ölçümüne yönelik birkaç ölçek bulunmaktadır. Bunlardan biri Karadağ ve ark. (2015) tarafindan geliştirilmiş 10 madde iki faktörden oluşan sosyotelizm ölçeğidir. Ancak bu ölçeğin, maddeleri ve faktörleri incelendiğinde sosyal bağlamda bir sosyotelizmin yanı sıra telefon bağımlılığını da ölçtüğü düşünülmektedir. Bunun dışında partner sosyotelizmi (Roberts ve David, 2016), işveren sosyotelizmi (Roberts ve David, 2017), sosyotelizme yönelik algılanan sosyal normlar ölçeği (Chotpitayasunondh ve Douglas, 2016), teknoloji ile bölünen yaşam örnekleri ölçeği (McDaniel ve Coyne, 2016) gibi ölçeklere rastlanmaktadır. Ancak bu ölçekler de kapsamı gereği sosyotelizme maruz kalma durumuna yönelik genellenebilir bulgular üretememektedir. Daha açı bir ifade ile alanyazında sosyotelizmin ölçümüne yönelik gerek hedef kitle gerekse maddelerin kapsayıcılı̆̆ 1 bağlamında en genellenebilir ölçümün, Chotpitayasunondh ve Douglas (2018a) tarafından geliştirilen sosyotelist olma ve sosyotelizme maruz kalma ölçekleri ile yapılabileceği düşünülmektedir. Bu bağlamda, çalışmanın amacı sosyotelizm konusunda iki farklı bakış açısı ile (sosyotelist olma ve sosyotelizme maruz kalma) problem çözümüne yönelik ölçümler yapılabilecek veri toplama araçlarının Türkçe alanyazına kazandırılmasıdır. Bu amaç doğrultusunda, çalışma sürecinde Genel Sosyotelist Olma (GSO) ve Genel Sosyotelizme Maruz Kalma (GSMK) ölçeklerinin Türkçeleştirilmesi çalışması yürütülmüştür.

\section{Yöntem}

Araştırma iki farklı ölçeğin Türkçeye uyarlanmasını temel almaktadır. Daha önceki bölümde sözü edildiği gibi sosyotelizm ve sosyotelizme maruz kalma konusunda alanyazına kazandırılmış iki farklı ölçek bulunmaktadır. Bu ölçekleri yeniden geliştirmek hem zaman hem de maliyet açısından uygun görülmemiştir. Ölçek uyarlama, alanyazına alan uzmanlarınca kazandırılmış geçerli ve güvenilir bir ölçeğin, dil ve kültürel bağlamda ifade bütünlüğü bozulmadan özgün dil ve kültürden hedef dil ve kültüre dönüştürülmesi süreci olarak tanımlanabilir (Deniz, 2007; Karakoç ve Dönmez, 2014). Bu nedenle araştırma kapsamında ölçek geliştirme süreci izlenmesine gerek duyulmamış, ölçek uyarlama yoluna gidilmiştir. Ölçek uyarlama süreci başlatılmadan önce özgün ölçeklerin yazarlarından e-posta yolu ile izin alınmıştır. Böylelikle ölçeğin uyarlamasının etik normlar doğrultusunda ilerlemesi sağlanmıştır. $\mathrm{Bu}$ amaçla araştırma nicel araştırma yaklaşımı çerçevesinde ölçek uyarlama süreci adımları izlenerek yürütülmüştür. Uyarlama sürecinde Sousa ve Rojjanasrirat (2011) ve Hambleton ve Patsula (1999) tarafından önerilen aşamalar sentezlenerek oluşturulan aşamalı bir süreç izlenmiştir. Sözü edilen aşamalar ve işlem adımları Şekil 1'de gösterilmiştir. 
Şekil 1. Ölçek uyarlama süreci adımları

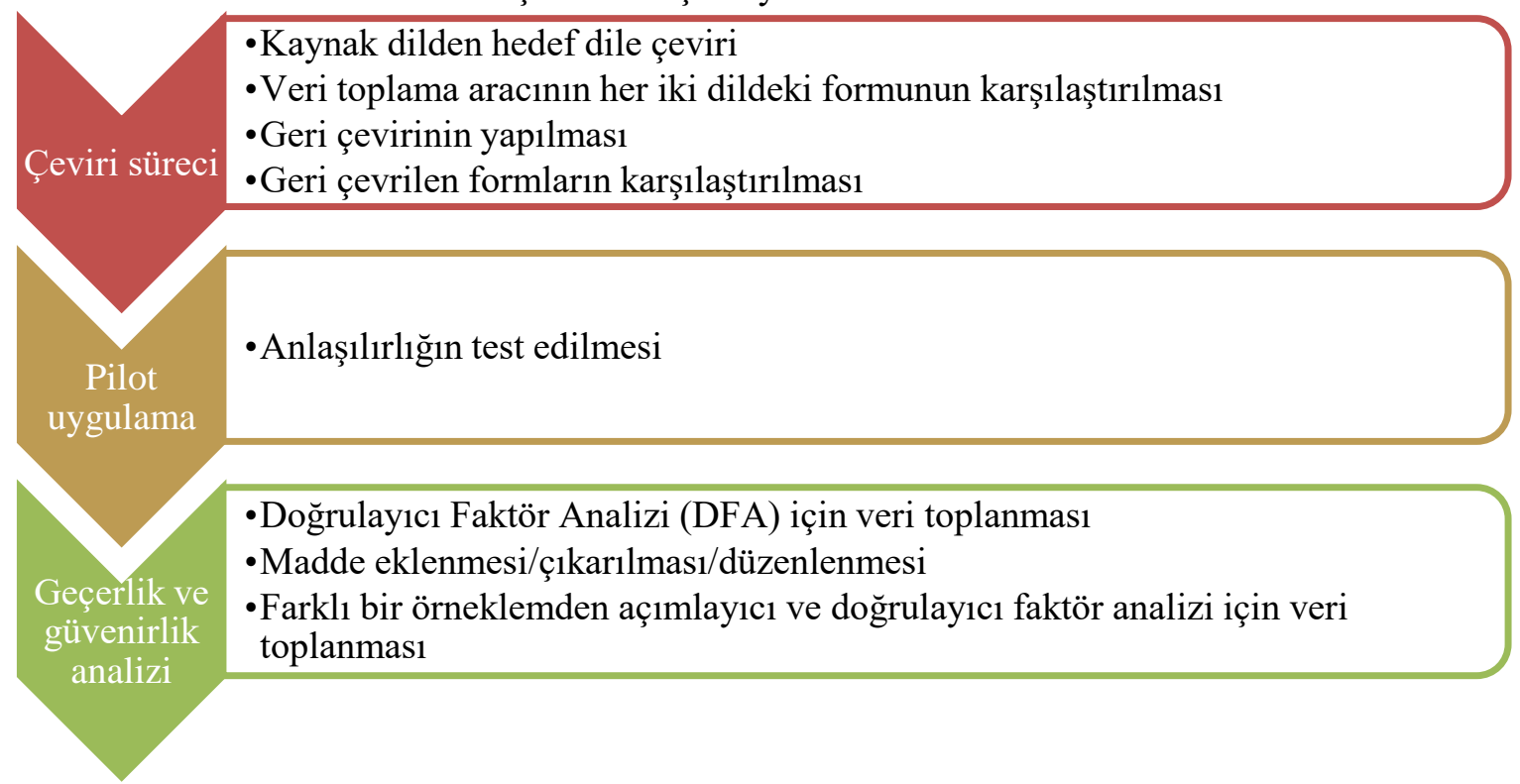

Şekil 1'de yer alan adımlar çerçevesinde çeviri sürecinde beş farklı uzmandan destek alınmıştır. Veri toplama araçlarının kaynak dilden hedef dile çevrilmesinde her iki dile hâkim iki, her iki dile hâkim ve alan bilgisine sahip bir uzman olmak üzere üç uzmanın çevirisi alınmıştır. Madde çevirileri araştırmacı ve bir Türkçe dil uzmanı tarafından karşılaştırmalı değerlendirilmiş ve en uygun çeviriler ile aday Türkçe formlar oluşturulmuştur. Oluş̧urulan Türkçe formlar her iki dile hâkim başka bir uzmana gönderilerek kaynak dile geri çevrilmeleri sağlanmıştır. Geri çeviriler ile kaynak formlar karşılaştırılmış ve maddelerin arasında anlamsal ve dilsel farklılık olmadığ 1 görüşüne varılmıştır. Ardından oluşturulan aday Türkçe formlar sekiz üniversite öğrencisine verilerek, her bir maddeye yönelik anlaşılmayan herhangi bir nokta olup olmadığı ve her bir maddeyi nasıl anladıkları sorulmuştur. Bu uygulamanın sonunda anlaşılmayan bir ifadenin olmadığı sonucuna ulaşılmış ve doğrulayıcı faktör analizi (DFA) için veri toplanmıştır. Toplanan veriler ile yapılan analizin sonucunda kaynak ve hedef formların birbirine benzer uyum değerlerine sahip olması nedeni ile ölçeklerin uyarlanması süreci tamamlanmıştır. Bir başka deyişle madde eklenmesi/çıkarılması/düzeltilmesi adımına gereksinim duyulmamış ve bu adım işe koşulmadığından yeni bir geçerlik güvenirlik çalışması yürütülmemiştir.

\subsection{Katılımcilar}

Araştırma kapsamında uyarlama analizleri için destek alınan iki farklı çalışma grubu oluşturulmuştur. İlk çalışma grubu anlaşılırlığın test edilmesi için görüşleri alınan sınıf öğretmenliği 2. sınıfta öğrenim görmekte olan 20 ve 21 yaşlarında sekiz kişiden oluşmaktadır. İkinci çalışma grubu kaynak ölçeğe bağlı kalınarak 18-35 yaş aralığında bulunan, 94'ü kadın 86'sı erkek 180 kişinin gönüllü katılımı ile DFA için veri toplanmıştır. Sözü edilen bu kişiler amaçlı örnekleme tekniklerinden ölçüte dayalı örnekleme tekniği ile belirlenmiştir. Ölçüte dayalı örnekleme tekniği; örneklemin problemle ilgili olarak belirlenen niteliklere/ölçütlere sahip kişiler, olaylar, nesneler ya da durumlardan oluşturulmasıdır (Büyüköztürk, Kılıç Çakmak, Akgün, Karadeniz ve Demirel, 2018). Örnekleme ölçütü, örneklemin kaynak ölçeğin geliştirildiği hedef kitleye olabildiğince benzer özellikler (yaş ve cinsiyet açısından) göstermesidir. Bu bağlamda araştırmacı görev yaptığı üniversitede çalışmaya katılmayı kabul eden öğrencilerden yaş bilgisi edinerek, bu yolla yaş ve cinsiyet çeşitlilik ve dengesini sağlamaya çalışmış ve araştırmanın örneklemi bu doğrultuda oluşturulmuştur.

\subsection{Verilerin Toplanması}


Verilerin toplanması süreci gönüllülük esasına bağlı olarak yürütülmüştür. Çeviri süreçlerinde uzmanların farklı yerlerde görev yapması nedeniyle, 2018 yılı Haziran ve Temmuz aylarında e-posta yolu ile iletişim kurularak çeviri verileri elektronik olarak toplanmış ve araştırmacı tarafından değerlendirilmiştir. Anlaşılırlığın test edilmesi sürecinde samimi görüş bildireceğine inanılan sekiz öğretmen adayı, 2018 Temmuz ayı sonunda aynı ortamda toplanarak maddeleri ayrıntılı biçimde incelemeleri sağlanmış ve madde anlaşılırlığı konusunda bir sorun olmadığı belirlenmiştir. Ortaya çıkan aday Türkçe form ile araştırmacı cinsiyet bağlamında dengeli, yaş bağlamında çeşitli bir dağılım olacak biçimde, 2018 yılı Ağustos ve Eylül aylarında veri toplamıştır. $\mathrm{Bu}$ veri toplama sürecinde katılımcıların gizliliklerinin korunacağı garanti edilerek yanıtlanması yaklaşık sekiz dakika süren veri toplama aracını yanıtlamaları istenmiştir. Araştırmaya katılımı kabul eden 180 öğretmen adayından yazılı form üzerinden veri toplanmıştır.

\subsubsection{Veri Toplama Araçlart}

Araştırmada veri toplama aracı olarak Chotpitayasunondh ve Douglas (2018a) tarafından geliştirilen GSO ve GSMK ölçeklerinin Türkçeleştirilmiş formları kullanılmıştır. Sözü edilen ölçeklerin ikisi de yedili likert tipinde (1=Asla, 2= Nadiren, 3= Ara sıra, 4= Bazen, 5= Slk sık, 6= Genellikle, 7= Daima) yanıtlanmaktadır. GSO 15 madde dört faktörden oluşan bir yapı ile sosyotelist olma durumunu \%52.56 açıklayan $(\alpha=0.93)$ bir ölçektir. GSMK 22 madde üç faktörden oluşan bir yapı ile sosyotelizme maruz kalma durumunu \%54.91 açıklayan $(\alpha=$ 0.96) bir ölçektir. Ölçek uyarlama adımları izlenerek bu ölçeklerin Türkçe formları oluşturulmuş ve araştırmanın bulguları bu formların ölçek durumuna getirilmesi üzerine kurulmuştur. Ölçeklerde ters puanlanan bir madde bulunmamaktadır. Toplam puan hesaplaması katılımcının verdiği yanıtının likert değerinin toplanması ile elde edilmektedir. Ölçeklerin maddeleri incelendiğinde tamamının, sosyal normlar ve genel kabul çerçevesinde olumsuz maddeler olduğu, buradan hareketle ölçeklerden alınan puanların yüksek olmasının olumsuz davranışla işaret ettiği belirtilebilir. Sözü edilen Türkçe formlar EK 1 ve EK 2'de yer almaktadır.

\subsection{Verilerin Analizi}

Araştırmada elde edilen veriler DFA ile analiz edilmiştir. DFA gizil değişken ya da değişkenlerin gözlenen değişkenler tarafindan açıklanması üzerine oluşturulan yol tanımlamalarının uygun olup olmadığı hipotezlerini test eden bir analiz tekniğidir (Thompson, 2004). Bir başka deyişle maddeler ve faktörler arasında tanımlanan yolların anlamlı ve uyum değerlerinin alanyazında kabul gören aralıklarda olması ölçek ile öne sürülen modelin doğrulandığı anlamına gelmektedir. Bu araştırma bir ölçek uyarlama çalışması olduğundan bir başka ölçüt de kaynak dildeki ölçek formu uyum değerlerinin hedef dile çevrilmiş ölçeğin uyum değerleri ile benzerlik göstermesidir. Bu doğrultuda veri analizi yürütülmüş ve çalışmanın bulgular bölümünde sunulmuştur.

\section{Bulgular}

Çalışmanın bu bölümünde Türkçeleştirilen GSO ve GSMK ölçeklerinin DFA sonuçları sırası ile raporlanmıştır. Bu doğrultuda istatistiksel bulguların oluşturulduğu DFA için veri toplanan araçların Türkçeleştirilmesi için dil geçerliği çalışmaları her iki araç için de ortak biçimde yürütülmüştür. Dil geçerliği çalışmalarının ilk aşamasında ölçek Türkçeye çevrilirken bir alan uzmanı olmak üzere, her iki dile yönelik ileri düzey becerisi olan üç uzmandan destek alınmıştır. Uzmanların yaptığı çeviriler araştırmacı ve bir Türkçe dil uzmanı tarafından değerlendirilmiş en uygun olduğu düşünülen madde seçilmiştir. Bu sürecin ardından yine her iki dil becerileri yüksek bir uzmanın seçilen maddeleri kaynak ölçeğin dili olan İngilizceye geri çevirmesi sağlanmıştır. Geri çevrilen maddeler ile özgün maddelerin büyük bir bölümünün aynı ve geri kalanlarının da anlamsal ve yapısal olarak benzer olması nedeniyle ölçeğin Türkçe aday formunun oluşturulmasına karar verilmiştir. Oluşan bu aday form sekiz öğretmen adayı ile yüz yüze görüşme ortamında tartışılmıştır. Öğretmen adaylarından her iki veri toplama aracını da 
okumaları ve yanıtlamaları istenmiştir. Bu uygulamanın ortalama sekiz dakika sürmesi veri toplama aracının doldurulmasının yaklaşık yedi dakika süreceği bilgisini vermiştir. Uygulamanın ardından öğretmen adaylarına “Anlaşılmayan bir madde var mı?” sorusu yöneltilmiş ve anlaşılmayan bir madde olmadığ 1 belirlenmiştir. Hemen ardından maddelere yönelik birer birer "Bu madde sizin için ne anlam ifade etti?" sorusu yöneltilmiştir. Bu yolla maddelerin katılımcılar tarafından yanlış anlaşılmasının ya da anlam karmaşası oluşmasının önüne geçilmiştir. Dil geçerlik çalışmalarının ardından oluşan Türkçe aday formlar ile 180 kişiden veri toplanarak DFA süreçleri yürütülmüştür.

\subsection{GSO Ölçeğinin Geçerlik ve Güvenirlik Bulguları}

Bu bölümde GSO ölçeğinin yol diyagramı, maddelerinin yük değerleri ve anlamlılıkları, uyum değerleri ve özgün ölçek ile uyum değerlerinin karşılaştırılmasına yönelik bulgular yer almaktadır. DFA kapsamında maksimum benzerlik yöntemi ile yürütülen analizin sonucunda maddeler ve faktörler arasındaki yolların anlamlılıkları yol diyagramı incelenerek belirlenmiştir. GSO ölçeği "nomofobi", "kişisel çatışma", "kendini yalnızlaştırma" ve "problem farkındalığı" olmak üzere dört faktör ve 15 maddeden oluşmaktadır. Bu 15 madde ile faktörler arasında özgün ölçekte önerilen yol tanımlamaları yapılmış ve uygunluğu yol diyagramı incelenerek analiz edilmiştir. Sözü edilen diyagram Şekil 2'de sunulmuştur.

Şekil 2. GSO ölçeği yol diyagramı

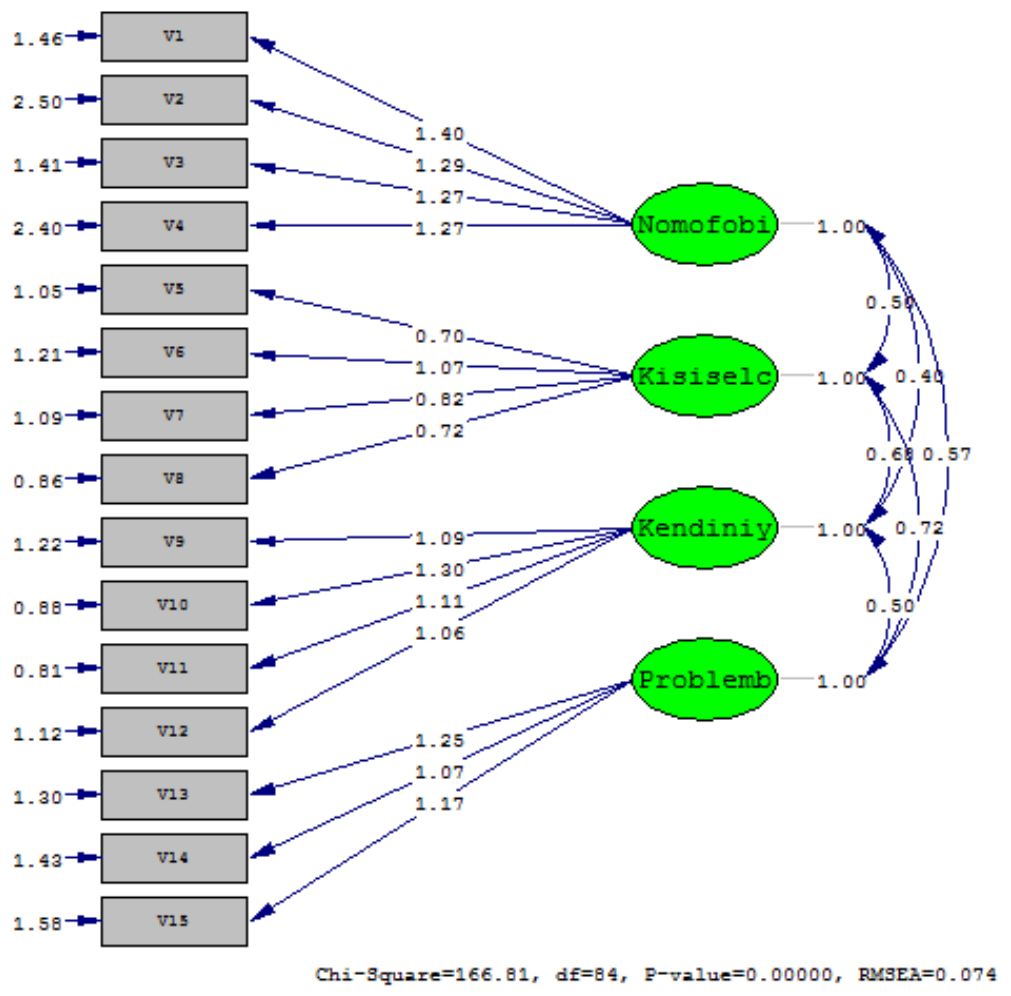

Şekil 2'de görüldüğ̈̈ gibi analiz kapsamında öne sürülen yolların tamamı anlamlıdır. Buradan yola çıkarak kaynak ölçek için çizilen bütün madde-faktör yollarının hedef ölçek için de geçerli olabileceği sonucuna ulaşılabilir. Ancak bu bulgu için tek başına yol diyagramı yeterli değildir. DFA ile yapı geçerliğine yönelik üretilen bir diğer bulgu olan maddelerin yük değerlerinin ve bu yüklerin anlamlılıklarının incelenmesi de gerekmektedir. GSO ölçeğinde bulunan Türkçe maddelerin oluşturdukları yük $\left(\mathrm{R}^{2}\right)$ ve bu yüklerin anlamlılığını gösteren $\mathrm{t}$ değerleri Tablo 3'te yer almaktadır. 
Tablo 3. GSO ölçeği maddelerinin $\mathrm{t}$ ve $\mathrm{R}^{2}$ değerleri

\begin{tabular}{lccc}
\hline \multicolumn{1}{c}{ Faktör adı } & Madde numaraları & $\mathrm{t}$ değerleri & $\mathrm{R}^{2}$ \\
\hline Nomofobi & 1 & 10.67 & 0.57 \\
& 2 & 8.57 & 0.40 \\
& 3 & 10.21 & 0.53 \\
& 4 & 8.57 & 0.40 \\
\hline Kişilerarası çatışma & 5 & 7.35 & 0.32 \\
& 6 & 9.54 & 0.49 \\
& 7 & 8.25 & 0.38 \\
\hline Kendini yalnızlaştırma & 8 & 8.14 & 0.37 \\
& 9 & 10.11 & 0.49 \\
& 10 & 12.30 & 0.66 \\
& 11 & 11.59 & 0.60 \\
Problem farkındalığı & 12 & 10.19 & 0.50 \\
& 13 & 10.14 & 0.55 \\
& 14 & 8.95 & 0.44 \\
& 15 & 9.20 & 0.47 \\
\hline
\end{tabular}

Tablo 3'te sunulan $\mathrm{R}^{2}$ değerleri incelendiğinde 0.32 ile 0.66 arasında değiştiği gözlenmektedir. $\mathrm{Bu}$ değerlerin anlamlı olup olmadığına yönelik incelenmesi gereken $\mathrm{t}$ değerlerinin de 7.35 ile 12.30 arasında değiştiği ve tamamının anlamlı olduğu $(p<0.001)$ görülmüsşür. Alanyazında iki ya da daha fazla faktörden oluşan yapılar için madde yüklerinin 0.32 ve üzeri bir değerde olmasının yeterli olduğu (Costello ve Osborne, 2005) öne sürülmüştür. $\mathrm{Bu}$ bakış açısı ile maddelerin oluşturduğu yük değerlerinin herhangi bir uyum sorunu oluşturmadığı yönünde bir sonuca ulaşılabilir. Bunlarla birlikte DFA ile üretilen bir diğer önemli sonuç ölçek yapısının uyum değerleridir. Uyum değerleri; analiz sırasında analiz programı tarafından önerilen modele yönelik ürettiği en iyi model ile araştırmacı tarafından önerilen modeli karşılaştırarak, bu iki model arasındaki benzerlikleri açılayan değerleridir (Barrett, 2007). Bu doğrultuda, araştırma bir uyarlama çalışması olduğundan, analiz programı tarafından üretilen Türkçe formun uyum değerlerinin alanyazında önerilen aralıklarda olmasının yanı sıra bu değerler ile özgün ölçeğin uyum değerlerinin benzerlik göstermesi de önemli görülmektedir. Sözü edilen uyum değerleri Tablo 4'te sunulmuştur.

Tablo 4. GSO ölçeğinin doğrulayıcı faktör analizi uyum değerleri ve karşılaştırması

\begin{tabular}{|c|c|c|c|c|}
\hline Uyum İndeksi & En İyi Uyum Değeri & Kaynak & $\begin{array}{l}\text { Özgün Ölçek } \\
\text { Uyum Değeri }\end{array}$ & $\begin{array}{l}\text { Türkçe Form } \\
\text { Uyum Değeri }\end{array}$ \\
\hline$\chi^{2} / \mathrm{sd}$ & $0 \leq \chi^{2} / \mathrm{sd} \leq 2$ & $\begin{array}{l}\text { (Tabachnick ve Fidell, } \\
\text { 2012) }\end{array}$ & 2.20 & 1.99 \\
\hline $\mathrm{p}$ & $.05 \leq \mathrm{p} \leq 1.00$ & (Hoyle, 1995) & $<0.001$ & 0.000 \\
\hline RMSEA & $0.5 \leq$ RMSEA $\leq 1.00^{*}$ & $\begin{array}{l}\text { (Schumacker ve } \\
\text { Lomax, 2004; } \\
\text { Thompson, 2004) }\end{array}$ & 0.06 & 0.07 \\
\hline SRMR & $0.5 \leq \mathrm{SRMR} \leq 1.00^{*}$ & (Kenny, 2010) & 0.04 & 0.06 \\
\hline NFI & $.80 \leq \mathrm{NFI} \leq 1$ & (Kenny, 2010) & 0.95 & 0.92 \\
\hline CFI & $.95 \leq \mathrm{CFI} \leq 1$ & (Hu ve Bentler, 1999) & 0.97 & 0.96 \\
\hline GFI & $.80 \leq \mathrm{GFI} \leq 1$ & (Bluch, 2008) & 0.93 & 0.89 \\
\hline
\end{tabular}

*Kabul edilebilir uyum değerlerini göstermektedir. 
GSO ölçeğinin Tablo 4'te sunulan uyum değerleri incelendiğinde, RMSEA ve SRMR değerleri kabul edilebilir uyum değerleri aralığında olduğu görülmektedir. Geriye kalan değerler ise, en iyi uyum değer aralıklarında olduklarından, ölçek kapsamında öne sürülen yapının analiz sonucunda elde edilen yapı ile iyi düzeyde uyum gösterdiğini işaret etmektedir. Bununla birlikte Türkçe ölçeğin $\chi^{2}$ sd oranının kaynak ölçek ile karşılaştırıldığında en iyi uyum değerleri sınırının içinde yer aldığı görülmektedir. Geriye kalan değerlerin birbirine yakın ve uyum değeri sınırları içinde yer aldığı göze çarpmaktadır. Ek olarak, uyum değerlerinin özgün ölçekle benzerlik gösterdiği ve alanyazında kabul edilebilir aralıklarda yer aldığı için herhangi bir hata tanımlaması ya da düzenlemeye gereksinim duyulmamıştır. Bunlarla birlikte ölçeğin güvenirlik analizi için Cronbach alpha $(\alpha)$ iç tutarlılık katsayısı incelenmiştir. Özgün ölçek ve Türkçe formun iç tutarlılık katsayısı karşılaştırmaları Tablo 5'te sunulmuştur.

Tablo 5. GSO ölçeği ve alt boyutlarının iç tutarlılık katsayısı karşılaştırması

\begin{tabular}{lll}
\hline İlgili boyut & Özgün Ölçek $\alpha$ & Türkçe Form $\alpha$ \\
\hline GSO & 0.93 & 0.86 \\
Nomofobi & 0.86 & 0.78 \\
Kişilerarası çatışma & 0.86 & 0.74 \\
Kendini yalnızlaştırma & 0.88 & 0.84 \\
Problem farkındalığı & 0.86 & 0.73 \\
\hline
\end{tabular}

Özdamar'a (2013: 555) göre Cronbach alpha iç tutarlılık katsayısı 0.70 ile 0.90 aralığında ise ölçeğin yüksek güvenirliğe sahip, 0.90'1n üzerindeyse çok yüksek güvenirliğe sahip olduğu söylenebilir. Buradan hareketle Tablo 5 'te sunulan değerler incelenmiş, gerek özgün ölçeğin $(0.86 \leq \alpha \leq 0.93)$, gerekse uyarlanmış formun $(0.73 \leq \alpha \leq 0.86)$ en az yüksek düzeyde güvenirliğe sahip olduğu görülmüştür. İç tutarlılık katsayılarının da diğer uyum değerlerinde olduğu gibi alanyazında sunulan ölçütlere uygun olduğu ve özgün ölçeğin değerler le paralellik gösterdiği görülmektedir. Tüm bu sonuçlar ışığında GSO ölçeğinin Türkçe formu ile İngilizce formunun uyum gösterdiği, başka bir ifade ile GSO ölçeğinin Türkçe uyarlamasının başarılı olduğu söylenebilir.

\subsection{GSMK Ölçeğinin Geçerlik ve Güvenirlik Bulguları}

$\mathrm{Bu}$ bölümde GSMK ölçeğinin uyarlanması sürecine yönelik analiz sonuçları raporlanmıştır. Raporlamada GSO ölçeği uyarlanma sürecinin raporlanması ile benzer bir yapı izlenmiştir. GSMK ölçeği algılanan normlar, ihmal edilmişlik hissi ve kişilerarası çatışma olmak üzere üç faktör 22 maddeden oluşmaktadır. Sözü edilen bu maddeler ve faktörler arasında tanımlanan yolların anlamlı olup olmadığı yol diyagramı incelenerek analiz edilmiştir. GSMK ölçeği yol diyagramı Şekil 3 ’te sunulmuştur. 
Şekil 3. GSMK ölçeği yol diyagramı

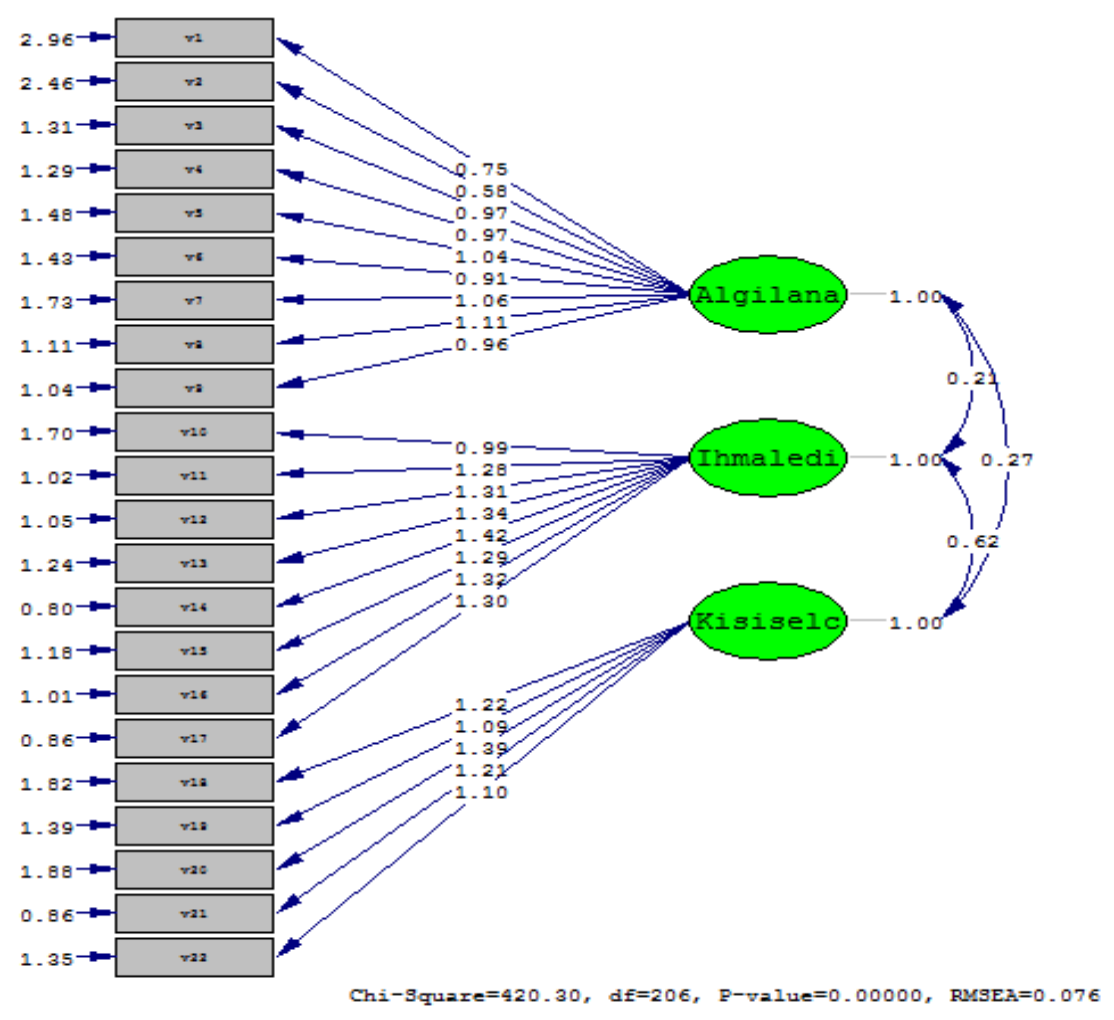

Şekil 3 incelendiğinde tanımlanan tüm yolların anlamlı olduğu görülmektedir. Diğer bir deyişle araştırma kapsamında toplanan verilerle üretilen en iyi model ile araştırmacı tarafından tanımlanan model arasında istatistiksel olarak anlamlı bir benzerlik bulunduğu görülmektedir. Yol diyagramına ek olarak, GSMK ölçeğinin özgün ölçek ile uyumunun test edilmesinde madde yükleri ve bu yüklerinin anlamlılıklarının incelenmesi gerekmektedir. Bu kapsamda incelenen $\mathrm{R}^{2}$ ve $\mathrm{t}$ değerleri Tablo 6'da yer almaktadır.

Tablo 6. GSMK ölçeği maddelerinin $\mathrm{t}$ ve $\mathrm{R}^{2}$ değerleri

\begin{tabular}{llll}
\hline Faktör adı & Madde numaraları & t değerleri & $\mathrm{R}^{2}$ \\
\hline Algılanan normlar & 1 & 5.19 & 0.16 \\
& 2 & 4.47 & 0.12 \\
& 3 & 9.09 & 0.48 \\
& 4 & 9.13 & 0.42 \\
& 5 & 9.14 & 0.42 \\
& 6 & 8.39 & 0.37 \\
& 7 & 8.73 & 0.39 \\
& 8 & 10.54 & 0.52 \\
& 9 & 9.83 & 0.47 \\
\hline İhmal edilmişlik hissi & 10 & 8.75 & 0.37 \\
& 11 & 12.41 & 0.62 \\
& 12 & 12.44 & 0.62 \\
& 13 & 12.00 & 0.59 \\
& 14 & 13.88 & 0.72 \\
& 15 & 11.94 & 0.59 \\
& 16 & 12.64 & 0.63 \\
& 17 & 13.07 & 0.66 \\
\hline Kişilerarası çatışma & 18 & 9.54 & 0.45 \\
& 19 & 9.70 & 0.46 \\
& 20 & 10.34 & 0.51 \\
& 21 & 11.99 & 0.63 \\
& 22 & 9.87 & 0.47 \\
\hline
\end{tabular}


Tablo 6'da görüldüğü gibi birinci ve ikinci madde dışında kalan tüm maddeler 0.37 ile 0.72 arasında değişen değerlerde yük oluşturmaktadır. Daha önce sözü edildiği gibi, çok faktörlü yapılarda bir maddenin bir faktörde en az 0.32 yük oluşturması beklenmektedir. Özgün ölçeğin DFA sürecinde birinci ve ikinci madde arasında bir hata tanımlaması yapılmıştır. Söz konusu durumun bu hata tanımlamasından kaynaklandığ 1 düşünülmektedir. EK 2'de sunulan birinci ve ikinci maddeler incelendiğinde, anlamsal olarak birbirine benzer oldukları ve ortaya çıkan bu durumun kaynağının da bu benzerlikten olabileceği düşünülmektedir. Bunlarla birlikte Tablo 5'te sunulan tüm $\mathrm{t}$ değerlerinin 4.47 ile 13.88 arasında değiştiği ve tamamının anlamlı $(p<0.001)$ olduğu görülmektedir. Bu değerlerden yola çıkarak, birinci ve ikinci maddeler için düşük ama anlamlı bir madde yükü oluşturdukları görüldügüünden model uyum değerlerinin incelenmesi uygun görülmüştür. Sözü edilen uyum değerleri Tablo 7'de sunulmuştur.

Tablo 7. GSMK ölçeğinin doğrulayıcı faktör analizi uyum değerleri ve karşılaştırması

\begin{tabular}{|c|c|c|c|c|}
\hline Uyum İndeksi & En İyi Uyum Değeri & Kaynak & $\begin{array}{l}\text { Özgün Ölçek } \\
\text { Uyum Değeri }\end{array}$ & $\begin{array}{l}\text { Türkçe Form } \\
\text { Uyum Değeri }\end{array}$ \\
\hline$\chi^{2} / \mathrm{sd}$ & $0 \leq \chi^{2} / \mathrm{sd} \leq 2$ & $\begin{array}{l}\text { (Tabachnick ve } \\
\text { Fidell, 2012) }\end{array}$ & 3.81 & 2.04 \\
\hline $\mathrm{p}$ & $.05 \leq p \leq 1.00$ & (Hoyle, 1995) & $<0.001$ & 0.000 \\
\hline RMSEA & $0.05 \leq \mathrm{RMSEA} \leq 1.00^{*}$ & $\begin{array}{l}\text { (Schumacker ve } \\
\text { Lomax, 2004; } \\
\text { Thompson, } \\
\text { 2004) }\end{array}$ & 0.09 & 0.08 \\
\hline SRMR & $0.05 \leq \mathrm{SRMR} \leq 1.00^{*}$ & (Kenny, 2010) & 0.05 & 0.07 \\
\hline NFI & $.80 \leq \mathrm{NFI} \leq 1$ & (Kenny, 2010) & 0.90 & 0.90 \\
\hline CFI & $.95 \leq \mathrm{CFI} \leq 1$ & $\begin{array}{l}\text { (Hu ve Bentler, } \\
\text { 1999) }\end{array}$ & 0.92 & 0.95 \\
\hline GFI & $.80 \leq \mathrm{GFI} \leq 1$ & (Bluch, 2008) & 0.82 & 0.82 \\
\hline \multicolumn{5}{|c|}{$\chi^{2}=783.77 ; \mathrm{sd}=206$} \\
\hline
\end{tabular}

*Kabul edilebilir uyum değerlerini göstermektedir.

GSMK ölçeğinin uyum değerleri incelendiğinde, RMSEA ve SRMR değerlerinin kabul edilebilir, geriye kalan uyum değerlerinin en iyi uyum aralıklarında olduğu görülmektedir. GSO ölçeğine paralel biçimde GSMK ölçeği verilerinden elde edilen $\chi^{2} /$ sd oranının ve CFI değerinin özgün form ile karşılaştırıldığında, daha iyi uyum gösterdiği söylenebilir. Bu değerlerle birlikte formun güvenirliğinin test edilmesinde Cronbach Alpha iç tutarlılık katsayıları incelenmiştir. Bu katsayılar Tablo 8'de karşılaş̧tırmalı biçimde sunulmuştur.

Tablo 8. GSMK ölçeği ve alt boyutlarının iç tutarlılık katsayısı karşılaştırması

\begin{tabular}{lll}
\hline İlgili boyut & Özgün Ölçek $\alpha$ & Türkçe Form $\alpha$ \\
\hline GSMK & 0.96 & 0.87 \\
Algılanan normlar & 0.92 & 0.83 \\
İhmal edilmişlik hissi & 0.94 & 0.92 \\
Kişilerarası çatı̧̧ma & 0.87 & 0.83 \\
\hline
\end{tabular}


Özdamar'a (2013: 555) göre Cronbach alpha iç tutarlılık katsayısı 0.70 ile 0.90 aralığında ise ölçeğin yüksek güvenirliğe sahip, 0.90'ın üzerindeyse çok yüksek güvenirliğe sahip olduğu söylenebilir. Bu bilgi ışı̆̆ında Tablo 8'de sunulan değerler incelendiğinde gerek özgün ölçeğin $(0.87 \leq \alpha \leq 0.96)$, gerekse uyarlanmış formun $(0.83 \leq \alpha \leq 0.92)$ en az yüksek düzeyde güvenirliğe sahip olduğu görülmektedir. İç tutarlılık katsayılarının da diğer uyum değerlerinde olduğu gibi alanyazında sunulan ölçütlere uygun olduğu ve özgün ölçeğin değerler le paralellik gösterdiği görülmektedir. Bu noktadan yola çıkılarak, GSMK ölçeğinin Türkçe uyarlamasının geçerli ve güvenilir bulgular ile sonuçlandırıldığı söylenebilir. Başka bir ifade ile araştırma kapsamında GSMK ölçeği Türkçeleştirilmesinin başarı ile gerçekleştirildiği söylenebilir.

\section{Sonuç, Tartışma ve Öneriler}

Çalışma kapsamında GSO ve GSMK ölçeklerinin Türkçeye uyarlanması çalışması yürütülmüştür. Uzman görüşleri, hedef kitle görüşleri ve DFA sonucunda elde edilen bulgular 1şığında sözü edilen ölçeklerin Türkçe dil ve kültür uyarlaması tamamlanmıştır. GSO ölçeğinin özgün ölçekte öne sürülen dört faktör 15 maddeden oluşan yapısı herhangi bir hata tanımlaması yapılmadan doğrulanmıştır $\left(\chi^{2} / \mathrm{sd}=1.99, \mathrm{p}<0.001, \mathrm{RMSEA}=0.07, \mathrm{SRMR}=0.06, \mathrm{NFI}=0.92\right.$, $\mathrm{CFI}=0.96, \mathrm{GFI}=0.89)$. Bununla birlikte yol diyagramında tanımlanan tüm yollar anlamlı ve $\mathrm{t}$ ve $\mathrm{R}^{2}$ değerlerinin uygun olduğu görülmüştür. Benzer biçimde GSMK ölçeğinin özgün formunda öne sürülen üç faktör 22 maddeden oluşan yapısı herhangi bir hata tanımlaması yapılmadan doğrulanmıştır $\left(\chi^{2} / \mathrm{sd}=2.04, \mathrm{p}<0.001, \mathrm{RMSEA}=0.08, \mathrm{SRMR}=0.07, \mathrm{NFI}=0.90\right.$, $\mathrm{CFI}=0.95$, GFI= 0.82). GSMK ölçeği için yol diyagramında tanımlanan yollar ve $t$ değerleri anlamlıdır. Ancak bu ölçeğin birinci ve ikinci maddelerinin $\mathrm{R}^{2}$ değerleri alanyazında belirtilen aralığın altındadır. Sözü edilen iki madde "Başkaları telefonlarında mesajlarını ve sosyal medyadaki gelişmeleri kontrol ederler." ve "Başkaları telefonlarını çevrimiçi olmak için kullanırlar." maddeleridir. Bu iki maddenin kültürel olarak yakın anlamlı olabileceği düşünülmektedir. $\mathrm{Bu}$ nedenle maddelerin birbirine yakın ve toplamda bir yük oluşturdukları $\left(\mathrm{R}_{\text {gsmk } 1}^{2}=0.16, \mathrm{R}_{\text {gsmk } 2}^{2}=0.12\right)$ düşünülmektedir. Buradan yola çıkılarak, geriye kalan istatistiksel değerlerin uygun olması nedeniyle bir düzenleme yapılmamış ve ölçek genelinde anlamsal bütünlügü bozmamak için madde çıkarma yoluna gidilmemiştir.

Türkçeleştirilmiş ölçeklerin uyum değerleri ve özgün ölçeklerin uyum değerleri karşılaştırmalı olarak incelendiğinde, gerek alanyazında belirtilen uyum değeri aralıklarına uygunluk gerekse birbirine yakınlıkları ile benzer sonuçlar elde edildiği görülmektedir. $\mathrm{Bu}$ sonuç çalışma kapsamında Türkçeleştirilen ölçeklerin uyarlanma süreçlerinin başarılı olduğunu göstermektedir. Bir başka deyişle çalışma kapsamında özgün dil ve kültürden Türkçeleştirilen ölçeklerin, Türkçe dil ve kültüründe geçerli ve güvenilir veri toplama araçları olduğunun kanıtlandığı söylenebilir. Bu noktada çalışmayla Türkçe alanyazına sosyotelizmin ölçümüne yönelik iki farklı bakış açısı sunan iki farklı ölçek kazandırıldığı düşünülmektedir.

GSO ölçeği alanyazında bulunan Karadağ ve ark. (2015) tarafından geliştirilen sosyotelizm ölçeğinden gerek özgün dilde yürütülmüş geçerlik ve güvenirlik süreçleri gerekse kapsamı bağlamında farklılıklar göstermektedir. Karadağ ve ark. (2015) ölçeğinin maddelerin bir bölümü bireysel anlamda telefon bağımlılığına yöneliktir. Telefon bağımlılı̆̆ı, günlük yaşamda telefon kullanımının kontrol edilemez ölçüde aşırı düzeye ulaşması (Hong, Chiu ve Huang, 2012) olarak tanımlanabilir. Ancak sosyotelizm telefon kullanımının sosyal ilişkiler üzerine olumsuz etkileri ile ilişkilidir. Bu bağlamda telefon bağımlılığının daha farklı bir kapsamda ölçülmesi gereken bir davranış olduğu düşünülmektedir. $\mathrm{Bu}$ nedenle Türkçe alanyazında daha özel bir bağlamda sosyotelizm ölçümü yapabilecek bir araca gereksinim duyulduğu düşünülerek GSO ölçeği Türkçeleştirilmiştir.

Sosyotelizme yönelik Türkçe alanyazında bir veri toplama aracına rastlanmamıştır. Uluslararası alanyazında bulunan sosyotelizme maruz kalma durumuna yönelik partner sosyotelizmi (Roberts ve David, 2016), işveren sosyotelizmi (Roberts ve David, 2017) ölçekleri ile GSMK ölçeği arasında karşılaştırma yapıldığında benzer bir durum göze çarpmaktadır. Sözü 
edilen ölçekler sosyotelizme maruz kalma durumunu daha sınırlı bağlamlarda ölçmeye yöneliktir. Partner sosyotelizmi ölçeği (Roberts ve David, 2016), eş ya da duygusal iliş̧ki yaşanan kişinin sosyotelist davranışlarına maruz kalmayı ölçmektedir. Sözü edilen ölçek bağlamsal olarak, eş ya da duygusal ilişki yaşanan partnerin telefon kullanımının kişisel etkilerine yönelik maddeler içerdiğinden genel bir ölçüm yapmamaktadır. Benzer biçimde, işveren sosyotelizmi ölçeği (Roberts ve David, 2017) iş etkinlikleri sırasında maruz kalınan işveren sosyotelist davranışlarına yönelik algıyı ölçmektedir. Sonuç olarak genel anlamda sosyotelizme maruz kalmaya yönelik Türkçe bir ölçek bulunmazken uluslararası alanyazında da daha özel bağlamlarda sosyotelist davranışlara maruz kalma ölçülmektedir. Bu nedenle GSMK ölçeği alanyazındaki diğer ölçekler ile karşılaştırıldığında özgündür.

Özetle, araştırma kapsamında ulusal alanyazına GSO ve GSMK ölçeklerinin kazandırıldığı düşünülmektedir. Türkçe uyarlaması gerçekleştirilen bu ölçeklerin kullanılarak yapılacak çalışmalar ile hem eğitsel hem disiplinler arası çalışmalara katkı sağlanacağı öngörülmektedir. Tüm bunlara ek olarak, veri toplama araçlarının farklı veri toplama araçları ile birlikte farklı örneklemler üzerinde denenmesi önerilmektedir. Bununla birlikte sosyotelizmin Türk kültüründeki yansımaları nitel araştırmalar ile desteklenerek daha ayrıntılı biçimde araştırılabilir. Sosyotelizm dışında teknoloji ve davranış biçimini birlikte inceleyen başka değişkenlerin de benzerlik gösterip göstermediği gerçekleştirilecek araştırmalar ile ortaya çıkarılabilir.

\section{Kaynakça}

Agostin, T.M. ve Bain, S.K. (1997). "Predicting Early School Success With Developmental and Social Skill Screeners. Psychology in the Schools", 34, 219-228.

Barrett, P. (2007). "Structural Equation Modelling: Adjudging Model Fit. Personality and Individual Differences", 42(5), 815-824.

Best, J. (2017). Images of Issues: Typifying Contemporary Social Problems. Routledge.

Blunch, N. J. (2008). Introduction to Structural Equation Modelling: Using SPSS and AMOS. Los Angeles: Sage Publications.

Büyüköztürk, Ş., Kılıç Çakmak, E., Akgün, Ö. E., Karadeniz, Ş. ve Demirel, F. (2018). Bilimsel Araştırma Yöntemleri, 24. Bask1, Ankara: Pegem Akademi.

Chotpitayasunondh, V. ve Douglas, K. M. (2016). How "Phubbing" Becomes the Norm: The Antecedents and Consequences of Snubbing Via Smartphone. Computers in Human Behavior, 63, 9-18.

Chotpitayasunondh, V. ve Douglas, K.M. (2018a). Measuring Phone Snubbing Behavior: Development and Validation of the Generic Scale of Phubbing (GSP) and the Generic Scale of Being Phubbed (GSBP). Computers in Human Behavior, 88, 5-17.

Chotpitayasunondh, V. ve Douglas, K.M. (2018b). The effects of "phubbing" on social interaction, Journal of Applied Social Psychology, 48(6), 304-316.

Costello, A.B. ve Osborne, J.W. (2005). Best Practices in Exploratory Factor Analysis: Four Recommendations for Getting The Most From Your Analysis. Practical Assessment, Research and Evaluation, 10(7), 1-9.

Dees, J. G. (2017). The Meaning of Social Entrepreneurship İçinde Case Studies in Social Entrepreneurship and Sustainability (s. 34-42). Routledge.

Deniz, Z. (2007). "Psikolojik Ölçme Aracı Uyarlama", Ankara Üniversitesi Eğitim Bilimleri Fakültesi Dergisi, 40(1), 1-16.

Diamanduros, T., Jenkins, S. ve Downs, E. (2007). Analysis of Technology Ownership and Selective Use Among Undergraduates. College Student Journal, 41(4): 970-976. 
Doel, M. ve Shardlow, S. M. (2017). Modern Social Work Practice: Teaching and Learning in Practice Settings. Routledge.

Good, T. L. ve Lavigne, A. L. (2017). Looking in Classrooms. Routledge.

Hambleton, R. K. ve Patsula, L. (1999). Increasing the Validity of Adapted Tests: Myths to be Avoided an Guidelines for Improving Test adaptation practices. http://www.testpublishers.org/assets/documents/volume\%201\%20issue\%201Increasing\%20 validity.pdf (Erişim Tarihi: 25.07.2018).

Hoyle, R. H. (1995). Structural Equation Modeling: Concepts, İssues, and Applications. London: Sage Publications.

Hong, F. Y., Chiu, S. I. ve Huang, D. H. (2012). A Model of the Relationship Between Psychological Characteristics, Mobile Phone Addiction and Use of Mobile Phones By Taiwanese University Female Students. Computers In Human Behavior, 28(6): 2152-2159.

Hu, L. ve Bentler, P. M. (1999). Cutoff Criteria for Fit Indexes in Covarience Structure Analysis: Conventional Criteria Versus New Alternatives. Structural Equation Modeling, 6: $1-55$.

Jacobsen, W. ve Forste, R. (2011). The Wired Generation: Academic and Social Outcomes Ofelectronic Media Use Among University Student. Cyberpsychology, Behavior, \& Social Networking, 14(5): 275-280.

Karadağ, E., Tosuntaş, Ş. B., Erzen, E., Duru, P., Bostan, N., Mizrak Şahin, B., Çulha, İ. ve Babadağ, B. (2015). Determinants of Phubbing, Which is The Sum Of Many Virtual Addictions: A Structural Equation Model. Journal Of Behavioral Addictions, 4(2): 60-74.

Karadağ, E., Tosuntaş, Ş. B., Erzen, E., Duru, P., Bostan, N., Mızrak-Şahin, B., Çulha, İ. ve Babadağ, B. (2016). "Sanal Dünyanın Kronolojik Bağımlılığı: Sosyotelizm (phubbing)", Addicta: The Turkish Journal on Addiction, 3(2): 223-269.

Karakoç, F. Y. ve Dönmez, L. (2014).” Ölçek Geliştirme Çalışmalarında Temel İlkeler”, Tip Eğitimi Dünyası,40: 39-49.

Krasnova, H., Abramova, O., Notter, I. ve Baumann, A. (2016). Why phubbing is toxic for your Relationship: Understanding the Role of Smartphone Jealousy Among "Generation Y" Users. ECIS (p. ResearchPaper109).

Kenny, D. A. (2010). Measuring Model fit. http://davidakenny.net/cm/fit.htm (Erişim Tarihi: 14.01.2018)

Ladd, G.W. (1990). Having Friends, Keeping Friends, Making Friends, and Being Liked By Peers in The Classroom: Predictors Of Children's Early School Adjustment? Child Development, 61: 1081-1100.

McDaniel, B. T. ve Coyne, S. M. (2016). Technoference: The Interference of Technology in Couple Relationships and Implications for Women's Personal and Relational Wellbeing. Psychology of Popular Media Culture, 5(1): 85.

Nazir, T. ve Pişkin, M. (2016). Phubbing: A technological İnvasion Which Connected The World But Disconnected Humans. Int J Indian Psychol, 3: 68-76.

Özdamar, K. (2013). Paket Programlar İle İstatistiksel Veri Analizi, Cilt I, 9. Baskı, Eskişehir: Nisan Kitabevi.

Roberts, J. A. ve David, M. E. (2016). My Life Has Become a Major Distraction From My Cell Phone: Partner Phubbing and Relationship Satisfaction Among Romantic Partners. Computers in Human Behavior, 54, 134-141. 
Roberts, J. A. ve David, M. E. (2017). Put Down Your Phone and Listen to Me: How Boss Phubbing Undermines The Psychological Conditions Necessary for Employee Engagement. Computers in Human Behavior, 75, 206-217.

Schumaker, R. E. ve Lomax, R. G. (2004). A Beginner's Guide To Structural Equation Modeling. 2. Bask1, New Jersey: Lawrence Erlbaum Associates, Publishers.

Sousa, V. D. ve Rojjanasrirat, W. (2011). Translation, Adaptation and Validation of Instruments or Scales for Use in Cross-Cultural Health Care Research: A Clear and User-Friendly Guideline, Journal Of Evaluation in Clinical Practice, 17(2), 268-274.

Tabachnick, B. G. ve Fidell, L. S. (2012). Using multivariate statistics. 6. Bask1, London: Pearson.

Thompson, B. (2004). Exploratory and Confirmatory Factor Analysis: Understanding Concepts and Applications. Washington DC: American Psychological Association. 


\section{Ekler}

Araştırmacı Beyanı: Bu çalışma kapsamında Türkçeleştirilmiş GSO ve GSMK ölçeklerini bilimsel amaçlar doğrultusunda kullanmak isteyen araştırmacıların, benimle iletişime geçmelerine gerek olmadan, okumakta olduğunuz bu çalışmayı kaynak göstererek ölçekleri kullanmalarını kabul ettiğimi, çalışmanın yazarı olarak beyan ederim.

\section{EK 1. GSO Ölçeği Maddeleri}

1. Telefonum yanımda olmadığında huzursuz olurum.

2. Telefonumu bırakıp çıkamam.

3. Telefonumu görebileceğim bir yere koyarım.

4. Telefonumu kontrol etmediğimde önemli şeyler kaçırmaktan korkarım.

5. Telefon kullanımım nedeniyle başkalarıyla tartışıyorum.

6. İnsanlar telefonumla çok uğraştığımı söylerler.

7. Başkaları bana telefonumu bırakmamı ve onlarla konuşmamı söylediğinde sinirlenirim.

8. Başkalarını rahatsız ettiğini bilsem bile telefonumu kullanırım.

9. Başkaları ile ilgilenmektense telefonumla ilgilenmeyi tercih ederim.

10. Başkalarındansa telefonumla ilgilendiğimde rahatlarım.

11. Başkalarına odaklanmayı bırakıp telefonumla ilgilendiğimde iyi hissederim.

12. Başkalarını görmezden gelip telefonumla ilgilendiğimde stres atarım.

13. Telefonumla planladığım zamandan daha fazla ilgilenirim.

14. Telefon kullanımım nedeniyle başkalarıyla konuşma fırsatlarını kaçırdığımın farkındayım.

15. Telefonumu kullanırken kendimi "sadece birkaç dakika daha" diye düşünürken bulurum.

\section{EK 2. GSMK Ölçeği Maddeleri}

1. Başkaları telefonlarında mesajlarını ve sosyal medyadaki gelişmeleri kontrol ederler.

2. Başkaları telefonlarını çevrimçi olmak için kullanırlar.

3. Başkaları telefonları görebilecekleri bir yere koyarlar.

4. Başkaları telefonunu kontrol etmediğinde önemli şeyler kaçırmaktan korkarlar.

5. Başkaları telefon kullanımları nedeniyle çevrelerine yönelik farkındalıklarını kaybederler.

6. Başkaları telefonlarını bıraktıklarında zor zaman geçiriyor gibi görünürler.

7. Başkaları telefonlarını bırakıp çıkamazlar.

8. Başkaları telefonunu kullanırken "kendi dünyalarında" gibi görünürler.

9. Başkaları telefonları yanlarında değilse huzursuz görünürler.

10. Başkaları benimle konuşmak yerine telefonları ile ilgilenirler.

11. Başkaları benimle konuşmaktansa telefonları ile ilgilenmeyi tercih ederler.

12. Başkaları beni görmezden gelip telefonuyla ilgilendiğinde sıkılmaktan kurtulmuş gibi görünürler.

13. Başkaları bendense telefonlarıyla ilgilendiğinde rahatlamış gibi görünürler.

14. Başkaları bana odaklanmaktansa telefonlarıyla ilgilenirler.

15. Başkaları bendense telefonlarıyla ilgilendiklerinde stres atmış gibi görünürler.

16. Başkaları bana odaklanmayı bırakıp telefonlarıyla ilgilendiklerinde iyi hissediyor görünürler.

17. Başkaları ilgilerini benden telefonlarına kaydırırlar.

18. Başkalarına telefonlarıyla çok uğraştıklarını söylerim.

19. Başkalarıyla onların telefon kullanımları yüzünden tartışırım.

20. Başkaları telefonlarını kullanırken kendimi "bıktım artık" diye düşünürken bulurum.

21. Başkaları beni sinirlendirdiğini bilseler de telefonlarıly ilgilenirler.

22. Başkaları onlara telefonunu bırakmalarını ve benimle konuşmalarını söylediğimde sinirlenirler. 